\title{
Influence of concentration and ratio of macro elements in culture medium on the regeneration of grape meristems in vitro
}

\author{
Anton Rebrov \\ All-Russian Research Institute named after Ya. I. Potapenko for Viticulture and Winemaking - \\ Branch of Federal State Budget scientific Institution «Federal Rostov Agricultural Research Center»
}

\begin{abstract}
Annotation. The results of studies on the development of culture medium for initiation grape meristems into in vitro culture in order to increase their regenerative capacity during recovery from chronic diseases are presented. In the improved medium, in comparison with analogs, the total content of macro salts was reduced and their ratio was optimized, taking into account their consumption and the characteristics of their absorption from the nutrient solution by the grape plant. In the course of testing the new culture medium, its effectiveness has been established for grape varieties from various ecological and geographical groups. A higher and more stable percentage of survival and regeneration of extremely small meristems have been established against the background of various modifications of the recipe for the traditionally used culture medium of Murashige and Skoog.
\end{abstract}

\section{Introduction}

Initiation to the culture medium in vitro is a very complex, laborious and responsible operation. Its main difficulty is that recovery from viruses and other chronic diseases most successfully occurs by using an extremely small explant size, which, as the most genetically stable object, is most often used by the apical meristem [1]. In the future, from the isolated apical meristem of the limiting small size (for grapes, this size is $\approx 100 \mu \mathrm{m}$ ), it is necessary to regenerate the whole plant. For this, researchers have developed biotechnological techniques, the basis of which is the creation of special sterile conditions (in vitro), for the cultivation of isolated explants on an artificial nutrient medium. Such an environment contains all the basic nutrients necessary for plants, macro and microelements, a carbon source (most often sucrose), some vitamins and amino acids, but phytohormones play a special role in it. The exogenous initiation of phytohormones is one of the main factors guiding the processes of morphogenesis in vitro [2]. At the beginning of the initiation of meristems into in vitro culture medium, for their development and removal of apical dominance, phytohormones from the group of cytokinins are used (for a grape plant, this is most often 6-BAP). Further, if necessary, gibberellins have been used to increase the length of internodes in the shoots, and auxins are used for their rooting. Considering the special importance of phytohormones, while improving biotechnological methods, most researchers pay the most attention to the issue of hormonal regulation. For various plant species and varieties that have specificity for cultivation in vitro, optimal concentrations 
and types of hormones, as well as their combination and proportions, are selected. The most rarely modified part of the nutrient medium is its mineral composition (macro and less often microelements). This is due, first of all, to the complexity of such experiments, since when changing the concentrations of macrosalts in the nutrient medium, it is necessary to take into account the peculiarities of their absorption by plants, their antagonism and synergism in various ratios and concentrations. At the same time, most often the majority of researchers in microcloning grapes use the prescription of the Murashige and Skoog (MS) medium as the basic mineral base [3-13]. Less common are works in which the authors use minor modifications of the mineral base of a given environment [14], or study the effectiveness of other typical environments against the background of MS [15-20]. Despite the fact that in most scientific works on microclonal reproduction of plants, researchers prefer the environment of MS, however this medium has a number of disadvantages due to the fact that it was developed for the cultivation of tobacco callus cells and its main disadvantage in the regeneration of meristems is a high salt concentration of $4.7 \mathrm{~g} / 1$. As a result, in order to absorb the elements dissolved in it, a plant needs to overcome an osmotic pressure of about $2.5 \mathrm{~atm}$., in case of initiation into culture medium; this is not a plant, but an extremely small area of the apical meristem. In addition to this disadvantage, it is necessary to point out the unbalanced ratio of macronutrients, taking into account their needs for grape plants. In the mineral basis of the MS culture medium, there is a large imbalance towards $\mathrm{N}, \mathrm{K}$ and $\mathrm{Cl}$ relatively to other elements; wherein a lot of nitrogen is represented by the ammonium form $\left(\mathrm{NH}_{4}\right)$, while plants prefer the nitrate form $\left(\mathrm{NO}_{3}\right)$, therefore $\mathrm{NH}_{4}$ remains in the medium when $\mathrm{NO}_{3}$ is absorbed, and upon absorption of $\mathrm{Ca}$ from $\mathrm{CaCl}_{2}$, a lot of not assimilated $\mathrm{Cl}$ remains, all of this contributes to the acidification of the nutrient medium. Acidification below $5.0(\mathrm{pH})$, in turn, negatively affects the absorption of phosphorus and magnesium, and also makes a number of trace elements toxic to plants. This is probably one of the factors that determine the need for the frequent transplants, at the stage of proliferation, of plant conglomerates when using the MS medium. All of the above determined the goal of our research to develop and test a nutrient medium formulation that would lack the inherent disadvantages of the MS culture medium, which would contribute to the improvement of the regeneration of the grapes meristems of extremely small sizes.

\section{Materials and methods}

The studies were carried out in the laboratory of biotechnology of All-Russian Research Institute named after Ya. I. Potapenko for Viticulture and Winemaking - Branch of Federal State Budget scientific Institution «Federal Rostov Agricultural Research Center» in 20142017, according to generally accepted methods in biotechnology. The research objects were the grape varieties from different ecological-geographical groups and complex interspecific hybrids. The meristems were initiated during the phase of active plant growth, June-July. The meristems were isolated from the upper part of green shoots, pre-cut into one-eyed cuttings with removed leaves and antennae. The prepared plant material was pre-sterilized with $70 \%$ ethanol aqueous solution and $20 \%$ sodium hypochlorite. Meristems were isolated in a laminar box under an MBS-9 binocular microscope with an illuminator. In order to free the plants from chronic diseases, meristems with a size of no more than $0.1 \mathrm{~mm}$ were isolated. After planting the meristems on nutrient media, the following cultivation conditions were maintained: temperature 23-24 ${ }^{\circ} \mathrm{C}$, illumination 2300-2500 lux, photoperiod 16/8 hours. Fifty meristems were planted in all variants of the experiment. The counts were done one month later. Statistical processing was carried out by the method of confidence intervals, using the "analysis package" program Excel MS Office 2010 with a confidence level of $95 \%$. Confidence intervals for indicators, expressed in $\%$, were 
calculated according to the method of E.B. Wilson. (1927). While developing a nutrient medium for the initiation and regeneration of meristems in in vitro culture, we took into account the summarized data on the ratio of nutrients in green shoots and grape leaves, based on the analysis of numerous studies by Stoev K.D. (1981), as well as the rules and criteria recommended in hydroponics when compiling nutrient media, also generalized by V. A. Chesnokov and Bazyrina E. T. (1960). The nutrient media differed only in the composition of macrosalts, all the other components such as microsalts, sucrose, vitamins, hormones, agar-agar, were added to all variants in the same amount. Comparative data on the ratio and concentration of macronutrients in nutrient media are presented in tables 1 and 2.

Table 1. The ratio of macronutrients (relative to nitrogen) in the tested nutrient media

\begin{tabular}{|l|l|l|l|l|l|l|l|l|l|}
\hline \multirow{2}{*}{ № } & \multirow{2}{*}{$\begin{array}{l}\text { Experiemental } \\
\text { variants }\end{array}$} & \multicolumn{6}{|c|}{ The ratio of macronutrients in the culture media to nitrogen } \\
\cline { 3 - 10 } & $\mathrm{N}$ & $\mathrm{P}$ & $\mathrm{K}$ & $\mathrm{Mg}$ & $\mathrm{S}$ & $\mathrm{Cl}$ & $\mathrm{Na}$ & $\mathrm{Ca}$ \\
\hline 1. & MS control & 1,00 & 0,05 & 0,93 & 0,04 & 0,06 & 0,33 & 0,005 & 0,19 \\
\hline 2. & MS $3 / 4$ & 1,00 & 0,05 & 0,93 & 0,04 & 0,06 & 0,33 & 0,008 & 0,19 \\
\hline 3. & MS $1 / 2$ & 1,00 & 0,05 & 0,93 & 0,04 & 0,06 & 0,33 & 0,010 & 0,19 \\
\hline 4. & AR & 1,00 & 0,13 & 1,22 & 0,12 & 0,15 & 0,05 & 0,060 & 0,34 \\
\hline min $^{*}$ & 1,00 & 0,15 & 0,35 & 0,12 & 0,10 & 0,01 & 0,010 & 0,60 \\
\hline max $^{*}$ & 1,00 & 0,35 & 1,20 & 0,25 & 0,20 & 0,15 & 0,150 & 1,40 \\
\hline
\end{tabular}

* The range of ratios of macronutrients in the young shoots and leaves of grapes

Table 2. The content of macronutrients in the tested nutrient media and the limits of their optimal values min and max

\begin{tabular}{|c|c|c|c|c|c|c|c|c|c|}
\hline \multirow[t]{2}{*}{ № } & \multirow{2}{*}{$\begin{array}{l}\text { Experiemental } \\
\text { variants }\end{array}$} & \multicolumn{8}{|c|}{$\begin{array}{l}\text { The content of macronutrients in the culture medium by ae, } \\
\mathrm{mg} / \mathrm{l}\end{array}$} \\
\hline & & $\mathrm{N}$ & $\mathrm{P}$ & $\mathrm{K}$ & $\mathrm{Mg}$ & $S$ & $\mathrm{Cl}$ & $\mathrm{Na}$ & $\mathrm{Ca}$ \\
\hline 1. & MS co & 841,6 & 38,8 & 782,2 & 36,6 & 48,1 & 281,2 & 4,9 & 158,8 \\
\hline 2. & MS 3/4 & 631,2 & 29,1 & 586,6 & 27,5 & 36,1 & 210,9 & 4,9 & 119,1 \\
\hline 3. & $\mathrm{MS} 1 / 2$ & 420,8 & 19,4 & 391,1 & 18,3 & 24,1 & 140,6 & 4,9 & 79,4 \\
\hline 4. & AR & 297,1 & 37,2 & 361,8 & 34,7 & 45,5 & 16,0 & 19,2 & 101,0 \\
\hline \multicolumn{2}{|c|}{ min* } & 56,0 & 12,0 & 59,0 & 12,0 & 20,0 & - & - & 12,0 \\
\hline \multicolumn{2}{|c|}{$\max *$} & 250,0 & 150,0 & 500,0 & 84,0 & 331,0 & - & - & 217,0 \\
\hline
\end{tabular}

*Recommended concentration range of macronutrients for growing plants in hydroponic solutions

As can be seen from the tables presented, in the various modifications of the MS nutrient medium, only the concentrations of macro elements have changed, however their ratio remains unchanged. At the same time, it is necessary to point out the high content of nitrogen, potassium and chlorine in MS the nutrient medium relatively to the other macronutrients. These disproportions in the ratio differ from the recommended levels according to the recommendations for the plant nutrition developed for hydroponics, and are not overcome by a multiple change in the concentration in MS $3 / 4$ and MS $1 / 2$. In the developed medium (AR), we tried to take into account these disadvantages, as well as to reduce the total concentration of macrosalts to $2.2 \mathrm{~g} / 1$.

The presented study consisted of two experiments (stages). In the first stage, on the background of the three modifications of the prescription of the MS culture medium, the developed by us culture medium was tested. Modifications of MS were multiple concentrations of macro-composition of 100, 75 and $50 \%$, these are 4.7, 3.5 and $2.4 \mathrm{~g} \mathrm{/}$, respectively, to study the effect of salt concentrations in the nutrient solution on the processes of meristem regeneration. At the second stage, for a more detailed study of the effectiveness of the developed prescription of the nutrient medium, we compared it with the best modification of $\mathrm{MS}^{3} / 4$. In total, at the second stage of the study, over 20 grape varieties 
from different ecological-geographical groups were involved in the course of three years to identify the effectiveness of the AR nutrient medium in terms of varietal specificity to in vitro conditions. In this work, due to the impossibility of presenting all the results, only varieties with the most typical reaction are shown.

\section{The discussion of the results}

The research on the influence of the concentration and ratio of macro elements in culture media was carried out in several stages. In the first experiment, three-fold modifications of the MS and the developed culture medium (AR) were compared. The results of the first experiment are shown in the Figure 1 and Table 3.

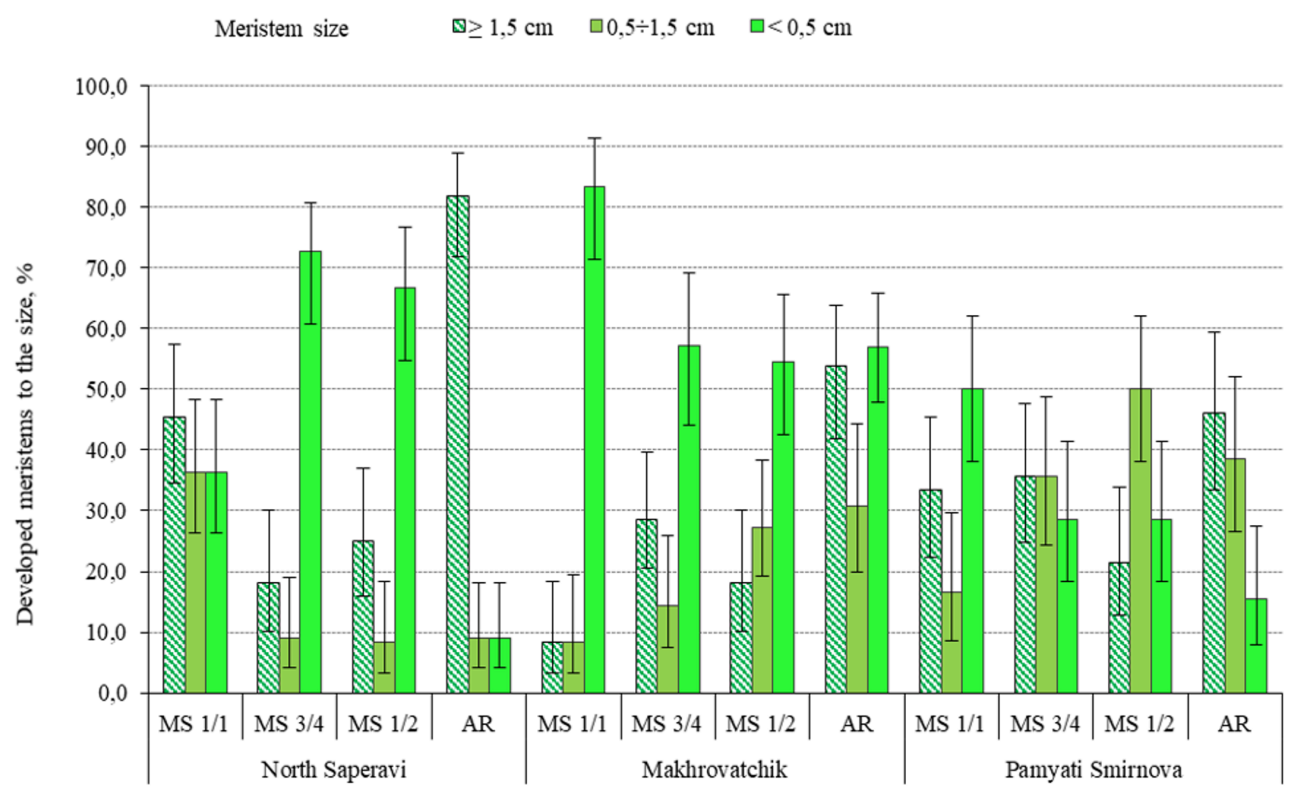

Fig. 1. Regeneration of meristems on culture media with various formulations of macrosalts

The study involved varieties from the different ecological-geographical groups. For the most varieties, a noticeable positive trend was noted in the second variant, in the modification of the MS medium with a reduced concentration of macrosalts from $4.7 \mathrm{~g} / 1$ to $3.5 \mathrm{~g} / 1$ of the medium. When using such a modification (MS3/4), in most varieties, a noticeable increase in the percentage of well-developed meristems $(\geq 1.5 \mathrm{~cm})$ was observed, of which after 2-4 weeks it will be highly likely to obtain well-developed conglomerates with adventive shoots and regenerate plants. Also, in the first experiment, the AR medium with a concentration of macrosalts in the nutrient solution of $2.2 \mathrm{~g} / 1$ was noted. In this variant, the indicators of good development of conglomerates from meristems were the most stable for all cultivars. In the variant with a nutrient medium according to the AR prescription, a noticeable increase in the number of well-formed conglomerates $(\geq 1.5 \mathrm{~cm})$ was noted compared to the control. In addition, in this variant, tissue necrosis occurred noticeably less often; also, the aging processes and the development of callus were slowed down. 
Table 3. The influence of the formulation of macro salts in the culture medium on the regeneration of the meristems at the stage of initiation into the in vitro culture in various grape varieties

\begin{tabular}{|c|c|c|c|c|}
\hline \multirow[b]{2}{*}{ Variant } & \multirow{2}{*}{$\begin{array}{c}\text { the } \\
\text { survivalrate, } \\
\%\end{array}$} & \multicolumn{3}{|c|}{$\begin{array}{c}\text { Identified developmental deficiencies in } \\
\text { explants, } \%\end{array}$} \\
\hline & & necrosis & $\begin{array}{l}\text { callus } \\
\text { formation }\end{array}$ & $\begin{array}{c}\text { absence of } \\
\text { development }\end{array}$ \\
\hline \multicolumn{5}{|c|}{ North Saperavi } \\
\hline Control MS (4,7 g/l) & $85,0^{+9,2^{*}} /{ }_{-13,2^{* * *}}$ & $28,0+13,7 /-10,5$ & $22,0^{+13,2 /-9,2}$ & $14,0+12,2 /_{-7,0}$ \\
\hline $\mathrm{MS} 3 / 4(3,5 \mathrm{~g} / \mathrm{l})$ & $84,0^{+7,7 /-12,5}$ & $16,0^{+12,5 /-7,7}$ & $12,0+11,8 /_{-6,4}$ & $12,0+11,8 /-6,4$ \\
\hline MS 1/2 $(2,3 \mathrm{~g} / \mathrm{l})$ & $80,0+8,8 /-13,0$ & $6,0+10,2 /-3,9$ & $6,0^{+11,8 /-6,4}$ & $12,0+11,8 /-6,4$ \\
\hline $\operatorname{AR}(2,2 \mathrm{~g} / \mathrm{l})$ & $90,0^{+5,7} /-11,4$ & $0,0^{+7,1} /_{-0,0}$ & $0,0^{+11,8 /-6,4}$ & $10,0^{+11,4 /-5,7}$ \\
\hline \multicolumn{5}{|c|}{ Makhrovatchik } \\
\hline Control MS (4,7 g/l) & $78,0^{+9,2 /-13,2}$ & $0,0+7,1 /-0,0$ & $0,0^{+7,1} /_{-0,0}$ & $24,0+13,4 /-9,7$ \\
\hline $\mathrm{MS} 3 / 4(3,5 \mathrm{~g} / \mathrm{l})$ & $100,0^{+0,0} /_{-7,1}$ & $0,0^{+7,1} / /_{-0,0}$ & $0,0^{+7,1} /_{-0,0}$ & $14,0+12,2 /_{-7,0}$ \\
\hline MS $1 / 2(2,3 \mathrm{~g} / \mathrm{l})$ & $88,0+6,4 /-11,8$ & $0,0+7,1 /{ }_{-0,0}$ & $0,0^{+7,1} /_{-0,0}$ & $8,0+10,8 /-4,8$ \\
\hline $\operatorname{AR}(2,2 \mathrm{~g} / \mathrm{l})$ & $94,0+3,9 /{ }_{-10,2}$ & $0,0+7,1 /{ }_{-0,0}$ & $0,0^{+7,1} /_{-0,0}$ & $6,0+10,2 /-3,9$ \\
\hline \multicolumn{5}{|c|}{ Pamyati Smirnova } \\
\hline Control MS (4,7 g/l) & $86,0^{+7,0} /-12,2$ & $28,0+13,7 /_{-10,5}$ & $10,0^{+11,4 /-5,7}$ & $10,0+11,4 /_{-5,7}$ \\
\hline MS 3/4 $(3,5 \mathrm{~g} / \mathrm{l})$ & $100,0^{+0,0} /-7,1$ & $36,0+13,9 /-11,9$ & $14,0+12,2 /_{-7,0}$ & $6,0+10,2 /-3,9$ \\
\hline MS 1/2 (2,3 g/l) & $100,0^{+0,0} /_{-7,1}$ & $22,0^{+13,2} /-9,2$ & $0,0^{+7,1} /_{-0,0}$ & $4,0^{+9,5 /-2,9}$ \\
\hline $\operatorname{AR}(2,2 \mathrm{~g} / \mathrm{l})$ & $96,0^{+2,9 /-9,5}$ & $6,0^{+10,2 /-3,9}$ & $0,0^{+7,1} /-0,0$ & $8,0+10,8 /-4,8$ \\
\hline
\end{tabular}

* Confidential interval of the upper limit; ** Confidential interval of the lower limit

At the same time, we noted that the following regularities such as the largest and smallest of the developed and retained viability of the meristems were more often on the medium according to the MS prescription. However, the smallest meristems on the experimental AR culture medium were larger than in the control medium, while no significant differences in the average size of the developed conglomerates were observed. On the developed culture medium, the greater percentage of regenerated and developed meristems was noticed, while tissue necrosis and callus formation occurred less often.

The results of the second part of the study, where the developed culture medium was compared with the best modification of $\mathrm{MS}^{3} / 4$, are presented in the Figures 2 and Table 4. For the most of the studied varieties, as in the previous experiment, the positive effect was noted when using the developed culture medium prescription. Its application contributed to the increase in the number of well-formed conglomerates $(\geq 1.5 \mathrm{~cm})$, of which plants can subsequently be regenerated most reliably and fast. 


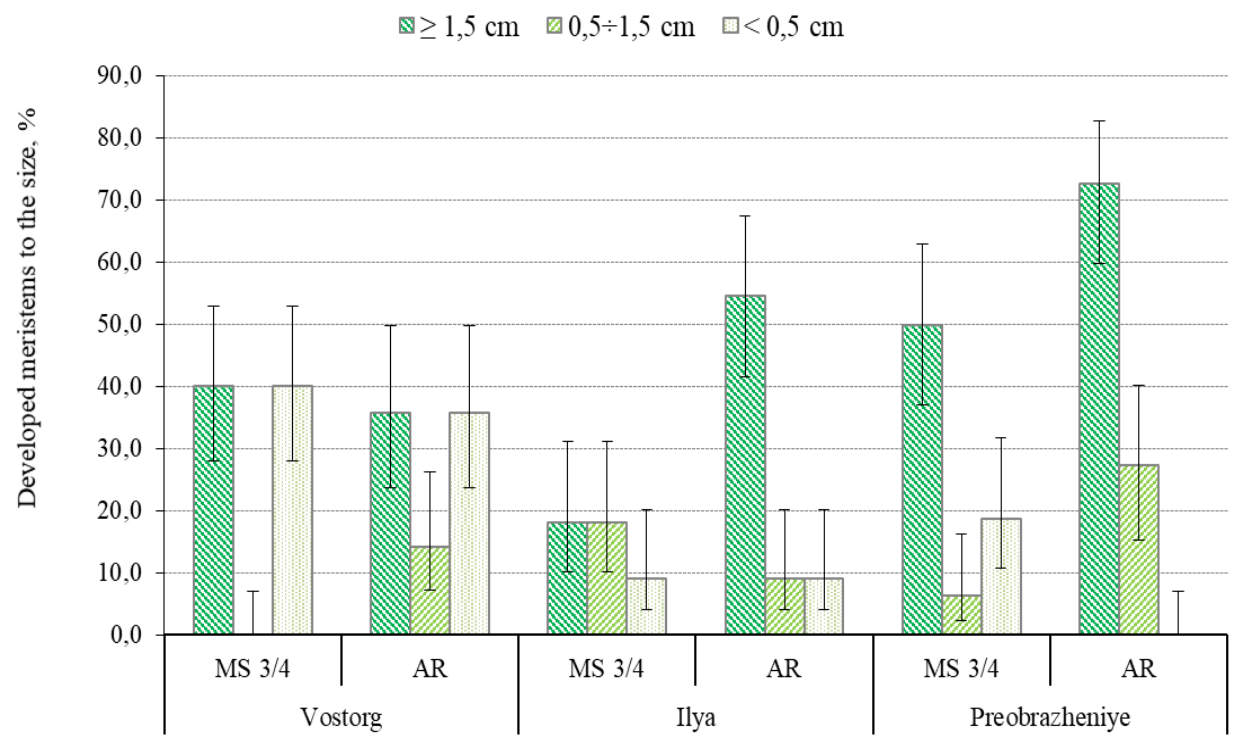

Fig. 2. The influence of the formulation of macrosalts in the culture medium on the regeneration of meristems at the initiation stage of in vitro culture

Table 4. The influence of the formulation of macrosalts in the culture medium on the indicators of meristem regeneration at the initiation stage of in vitro culture in various grape varieties

\begin{tabular}{|c|c|c|c|c|}
\hline \multirow{2}{*}{ Variant } & \multirow{2}{*}{$\begin{array}{l}\text { the survival } \\
\text { rate, } \%\end{array}$} & \multicolumn{3}{|c|}{$\begin{array}{l}\text { Identified developmental deficiencies in } \\
\text { explants, } \%\end{array}$} \\
\hline & & necrosis & $\begin{array}{l}\text { callus } \\
\text { formation }\end{array}$ & $\begin{array}{c}\text { absence of } \\
\text { development }\end{array}$ \\
\hline \multicolumn{5}{|c|}{ Vostorg } \\
\hline MS $3 / 4(3,5 \mathrm{~g} / \mathrm{l})$ & $80,0+8,8 /-13,0$ & $10,0^{+11,4} /_{-5,7}$ & $12,0+11,8 /-6,4$ & $20,0^{+13,0} /_{-8,8}$ \\
\hline $\operatorname{AR}(2,2 \mathrm{~g} / \mathrm{l})$ & $86,0^{+7,0} /_{-12,2}$ & $0,0^{+7,1} /{ }_{-0,0}$ & $0,0^{+7,1} /{ }_{-0,0}$ & $14,0^{+12,2 /-7,0}$ \\
\hline \multicolumn{5}{|c|}{ Ilya } \\
\hline MS $3 / 4(3,5 \mathrm{~g} / \mathrm{l})$ & $46,0^{+13,6} /-13,0$ & $28,0+13,7 /-10,5$ & $8,0^{+10,8 /-4,8}$ & $44,0^{+12,8 /-13,7}$ \\
\hline $\operatorname{AR}(2,2 \mathrm{~g} / \mathrm{l})$ & $72,0+10,5 /-13,7$ & $18,0+12,8 /{ }_{-8,2}$ & $0,0^{+7,1} /{ }_{-0,0}$ & $26,0+13,6 /-10,1$ \\
\hline \multicolumn{5}{|c|}{ Preobrazheniye } \\
\hline $\mathrm{MS} 3 / 4(3,5 \mathrm{~g} / \mathrm{l})$ & $76,0^{+9,7} /-13,4$ & $16,0^{+12,5 /-7,7}$ & $16,0^{+12,5 /-7,7}$ & $8,0^{+10,8 /-4,8}$ \\
\hline $\operatorname{AR}(2,2 \mathrm{~g} / \mathrm{l})$ & $96,0^{+2,9} /-9,5$ & $6,0+10,2 /-3,9$ & $4,0^{+9,5 /-3,9}$ & $2,0+9,5 /-1,6$ \\
\hline
\end{tabular}

As in the previous experiment, when using the new culture medium, the increase in the percentage of well-developed meristems $\geq 1.5 \mathrm{~cm}$ was noted, which is the main positive sign during the initiation into in vitro culture; at the stage of proliferation, meristems could develop better and form shoots since at the stage of initiation the meristems reached this size. The greatest effect was obtained in the varieties Makhrovachik and Ilya, which, due to the manifested variety-specificity, would be difficult to regenerate without using the AR culture medium. In virtue of the use of new recipe of macroelements, it was possible to improve the development of meristems at the stage of initiation into in vitro culture and to increase the meristems adaptability by the average of $20-30 \%$, depending on the variety. 


\section{Conclusion}

The most effective modification of MS culture medium for the initiation of grape meristems into the in vitro culture is its use in the concentration $3 / 4$ of macroelements from the prescription. However, it is not always possible to successfully overcome the varietal specificity, and the negative impact on the processes of morphogenesis in vitro, such as the development of callus, rapid aging of conglomerates and tissue necrosis. The testing of the developed recipe of macronutrients showed the effectiveness of its application on all introduced varieties. At the same time, it could be assumed that all this happens due to the optimization of the concentrations and ratio in the culture medium: $\mathrm{NH}_{4}$ and $\mathrm{NO}_{3}$, total $\mathrm{N}$ and $\mathrm{K}, \mathrm{Ca}$ and $\mathrm{K}, \mathrm{P}$ and $\mathrm{Mg}$, the decrease in the $\mathrm{Cl}$ content, and the addition of the optimal $\mathrm{Na}$ concentration.

\section{References}

1. K.A. Quiroz, M. Berríos, B.Carrasco, J.B. Retamales, P.D.S. Caligari1, R. GarcíaGonzáles, Quiroz et al. Biol Res 50 (20), 1-11 (2017), https://doi.org/10.1186/s40659-017-0125-8

2. K. Fikadu, Int. J. Agril. Res. Innov. Tech. 10(1): 1-5, (2020) https://doi.org/10.3329/ ijarit.v10i1.48087

3. K. Fikadu, F. Tileye, Afr. J. Biotechnol., 18(4), 92-100 https://doi.org/10.5897/AJB2018.16700

4. M.F. Lazo-Javalera, R. Troncoso-Rojas,

M.E. Tiznado-Hernández, SpringerPlus,5(453), 1-9 (2016) https://doi.org/10.1186/s40064-016-2081-0

5. K. Nadra, A. Maqsood, H. Ishfaq, A, Nadeem, E. Shaghef, M. Anjum, J. Int. Sci. Vigne Vin, 49, 37-45 (2015) https://doi.org/10.20870/oeno-one.2015.49.1.95

6. S. Amiri, R. Mohammadi, R. Akbari, Erwerbs-Obstbau, 61， 85-92 (2019) https://doi.org/10.1007/s10341-019-00456-y

7. B. Kinfe, T. Feyissa, G. Bedada, Afr. J. Biotechnol., 16(43), 2083-2091 (2017) https://doi.org/10.5897/AJB2016.15803

8. A. Naila, A. Humera, A. Sabahat, International Journal of Advances in Biology (IJAB), 4, 01-11 (2017) https://doi.org/10.5121/ijab.2017.4301

9. O. Alvarado-Gómez, G. Moreno-Degollado, R Humberto, J. Cavazos-Galindo, A. Santos-Haliscak, M. Ojeda-Zacarías, Polibotánica, 45, 181-190 (2018) https://doi.org/10.18387/polibotanica.45.13

10. Md. Arifuzzaman, S. Sultana, Md.S. Hossain, Saifullah, Rifat-Al-Naser, S. Alim, Md.J.Hasan, Sch J Agric Vet Sci, 3(4), 326-331 (2016) https://doi.org/10.21276/SJAVS.2016.3.4.11

11. K. Motha, S.K. Singh, R. Singh, C. Ram, M. Srivastav, M.K. Verma, M. Alizadeh, Ch. Bhardwaj, D. Rahul, Indian Journal of Horticulture, 74, 317-325 (2017) https://doi.org/10.5958/0974-0112.2017.00065.2

12. F.M.A. Mostafa, M.M. Shaaban, D.S. Elazab, M.T. Kamel, Assiut J. Agric. Sci., 46 (4), (65-76)2015 https://www.researchgate.net/publication/299853794

13. N.P. Dorochenko, V.G. Puzirnova, Fruit growing and viticulture in the South of Russia, 64(4), 190-209 (2020)https://doi.org/10.30679/2219-5335-2020-4-64-190-209

14. N. C. Surakshitha, K. Soorianathasundaram, M. Ganga, M. Raveendran, Sci. Hortic., 248, 118-125(2019), https://doi.org/10.1016/j.scienta.2019.01.013 
15. H. Yildirim, G. Ozdemir, Erwerbs-Obstbau, 60, 55-59(2018) https://doi.org/10.1007/ s10341-018-0393-7

16. A.D. Ayman, S.M. Khalil, M.I. Roba, Int. J. Adv. Biotechnol. Res, 2(4), 484-491 (2011) https://www.researchgate.net/publication/251875083

17. O.V. Matushkina, I.N. Pronina, D.G. Shornikov, I.V. Michurin, Achievements of Science and Technology of AIC, 33 (2), 14-16 (2019) https://doi.org/10.24411/02352451-2019-10204

18. T. San Pedro, R. Peiró, J. Villanova, A. Olmos, C. Gisbertn, Electron. J. Biotechn., 27, 80-83 (2017) https://doi.org/10.1016/j.ejbt.2017.03.006

19. Z.A. Rahman, M.A.M. Shukri, G.M. Norfaizal, A. Khadijah, A.N. Othman, Biosci. Biotech. Res. Asia, 15 (1), $51-58$ (2018) https://doi.org/10.13005/bbra/2607

20. P. Mukherjee, N. Husain, S.C. Misra, V.S. Rao, Sci. Hortic., 126(1), 13-19 (2010) https://doi.org/10.1016/j.scienta.2010.06.002 